\title{
Efficacy and safety of topical calcineurin inhibitors for the treatment of atopic dermatitis: meta-analysis of randomized clinical trials
}

\author{
Natalia Łabędź, Rafał Pawliczak² \\ ${ }^{1}$ Hirszfeld Institute of Immunology and Experimental Therapy, Polish Academy of Sciences, Wroclaw, Poland \\ 2Department of Immunopathology, Chair of Allergology, Immunology and Dermatology, Medical University of Lodz, Lodz, Poland \\ Adv Dermatol Allergol 2019; XXXVI (6): 752-759 \\ DOI: https://doi.org/10.5114/ada.2019.91425
}

\begin{abstract}
Introduction: Calcineurin inhibitors, novel topical immunomodulators, may constitute a superior alternative for glucocorticosteroids in atopic dermatitis (AD) topical treatment.

Aim: Determination of efficacy and safety of each topical calcineurin inhibitor (TCI) formulation, $0.3 \%$ or $0.1 \%$ tacrolimus and 1\% pimecrolimus, for the treatment of moderate to severe AD in comparison with glucocorticosteroids. Material and methods: Cochrane Central Register of Controlled Trials (CENTRAL), MEDLINE, EMBASE, GREAT database, trials registers and reference lists were searched up to February 2018. Randomised controlled trials of $\mathrm{TCl}$, compared to corticosteroids (TCS), reporting efficacy or safety outcomes were selected. Quality of trials and evidence of each outcome were evaluated according to Cochrane Collaboration recommendations and tools. The primary outcomes were physician's global assessment of improvement and occurrence of adverse events (AEs). Results: Fourteen trials involving 7376 children and adults with AD were included. Calcineurin inhibitors were significantly more effective than various potency TCS, neither least potent to lower mid-strength nor mid-strength to potent TCS ( $R R=1.24,95 \% \mathrm{Cl}: 1.06-1.44)$. The major AEs were skin burning and pruritus, their incidence was higher in $\mathrm{TCl}$ treatment $(\mathrm{RR}=3.32,95 \% \mathrm{Cl}: 2.90-3.80 ; \mathrm{RR}=1.59,95 \% \mathrm{Cl}: 1.34-1.80)$.
\end{abstract}

Conclusions: Calcineurin inhibitors seem to be more effective and contrarily they elicit more AEs than TCS.

Key words: atopic dermatitis, calcineurin inhibitors, corticosteroids, tacrolimus, meta-analysis.

\section{Introduction}

Atopic dermatitis (AD) is a chronic inflammatory skin disease, which affects both children and adults. Atopic dermatitis is associated with pruritus, lichenification, chronically relapsing course and atopic history, personal or familial [1-3]. The origin of AD is complex; genetic, immunologic and environmental factors may be involved $[3,4]$. Its development and progression are highly connected with a skin barrier dysfunction, resulting in increased transepidermal water loss, higher propensity to microbial infections or facilitation of allergen skin penetration [5, 6]. The course of dermatitis remarkably affects the quality of life of patients and their families [7, 8].

Treatment of $A D$ is complex and includes daily skin care, allergen avoidance or use of topical remedies [3, 5]. Currently, topical corticosteroids (TCS) are the first-line therapy for patients with $\mathrm{AD}$ [9]. Their efficacy is briefly proven; none- theless, $A D$ is a disease with a chronic course and usually requires long-term, constant treatment. Long-standing TCS therapy presents a clear risk of adverse events (AEs) [4, 9]. Alternative treatment options with fewer side effects are being considered to overcome this issue, revealing calcineurin inhibitors (TCI) as a brilliant replacement for topical treatment. However, comparing with TCS, they are novel remedies in $\mathrm{AD}$ treatment and despite indisputable efficacy, the risk of AEs is still in question. Nowadays they are used as a second-line therapy option [10, 11].

\begin{abstract}
Aim
This review aimed at determination if $\mathrm{TCl}$ are a superior alternative for TCS and comparison of these two therapies in terms of their efficacy and safety. The study is of great importance to help establish novel guidance
\end{abstract}

Address for correspondence: Prof. Rafal Pawliczak MD, PhD, Department of Immunopathology, Medical University of Lodz, 7/9 Zeligowskiego, 90-752, Lodz, Poland, phone: +48 422725301 or 02, email: rafal.pawliczak@csk.umed.lodz.pl Received: 6.05.2019, accepted: 28.06.2019. 
to AD therapy, treatment of the disease affecting an increasing number of people.

\section{Material and methods}

The systematic review was conducted in accordance with the Preferred Reporting Items for Systematic Reviews and Meta-Analyses statement (PRISMA) [12]. No review protocol was registered.

\section{Search strategy and data collection}

A systematic review of the Cochrane Central Register of Controlled Trials (CENTRAL) (of 1980), MEDLINE via Ovid (of 1946), EMBASE via Ovid (of 1988), EMBASE via Ovid (of 1988), Global Resource of Eczema Trials (GREAT database) databases was performed up to 22 February 2018. Search terms included (eczema OR neurodermatitis OR atopic dermatitis) AND (tacrolimus OR protopic OR fk506 OR pimecrolimus OR elidel). Six trials registers were searched (metaRegister of Controlled Trials, US National Institutes of Health Ongoing Trials Register, Australian New Zealand Clinical Trials Registry, World Health Organization International Clinical Trials Registry platform, EU Clinical Trials Register, Ongoing Skin Trials Register). Bibliographies of identified articles were manually screened to find further references to relevant studies.

\section{Study selection}

Searched records were merged to remove duplicates, followed by examination of titles and abstracts of the remaining trials. Selected relevant studies were fully read for compliance with the eligibility criteria. Inclusion criteria were as follows: (1) randomized controlled trials, (2) people diagnosed with AD by a physician or other specialist using standardized diagnostic criteria of Hanifin and Rajka [1], (3) comparison of TCl and TCS treatments, (4) inclusion of at least one outcome of interest.

Pre-specified primary outcomes included physician's global assessment of improvement and occurrence of AEs. Pre-specified secondary outcomes included efficacy of treatment assessed by a validated or objective measure: affected Body Surface Area (BSA), Eczema Area and Severity Index (EASI) and modified EASI (mEASI). Studies which did not provide any data concerning efficacy or safety were excluded from analysis. Subgroup analysis was performed for mid-strength to potent and least potent to lower mid-strength TCS. For missing or unavailable data, sponsors websites or clinical trials reports were searched to derive needed information. Whenever possible, results from intention-to-treat (ITT) population were used.

\section{Quality of assessment}

Quality of evidence provided by the studies was evaluated using Grading of Recommendations Assessment, Development and Evaluation (GRADE) criteria [13]. The risk of bias analysis was performed using the Cochrane Collaboration Risk-of-Bias Tool for randomized controlled trials [14]. It incorporated the following aspects: random sequence generation, allocation concealment, blinding of participants and personnel, blinding of the outcome assessment, analysis of incomplete outcome data, selective reporting, and other biases.

\section{Statistical analysis}

The risk ratio (RR) and 95\% confidence intervals (Cls) were calculated for dichotomous outcomes. For continuous variables with a similar scale, mean differences (MD) and $95 \%$ Cls were calculated. If outcomes for continuous data used different scales, standardized mean differences (SMD) and 95\% Cls were calculated. When the study did not provide necessary information, it was omitted in a part of analysis. Results were considered to be statistically significant if $95 \% \mathrm{Cls}$ did not include the null value $(R R=1)$ and $p \leq 0.05$. Heterogeneity across studies was assessed using $P^{2}$ statistics [14], which describes the percentage of the variability in effect estimates that is due to heterogeneity rather than sampling error. If subgroup or total $R^{2}$ was assessed $>50 \%$, indicating possible substantial heterogeneity, a random effects model was used, otherwise the fixed model was applied. Analysis of data was conducted using Review Manager 5.3 (The Cochrane Collaboration).

\section{Results}

\section{Study selection}

Electronic search, shown in Figure 1, revealed 736 non-duplicative individual studies, from which $705 \mathrm{did}$ not meet inclusion criteria after abstract screening. The remaining 31 were examined as a full text, excluding other 17 articles. Finally, 14 studies were incorporated in qualitative and quantitative analysis.

\section{Characteristics of the studies}

Table 1 summarizes characteristics of included articles. All included studies were randomized controlled trials. A total number of 7376 participants were included into analysis. Corticosteroids therapy comprises various potency drugs, eight studies [15-22] examined least potent to lower mid-strength corticosteroids and only five [2, 23-26] mid-strength to potent drugs. Twelve studies $[2,15-23,26]$ addressed both primary outcomes, namely physician's global assessment of improvement and AEs, one [25] addressed AEs only. One study described secondary outcomes only [27].

\section{Outcomes}

Physician's global assessment of improvement: clear or excellent (Figure 2)

Neither comparison of mid-strength to potent TCS with $\mathrm{TCl}$ nor least potent to lower mid-strength TCS 


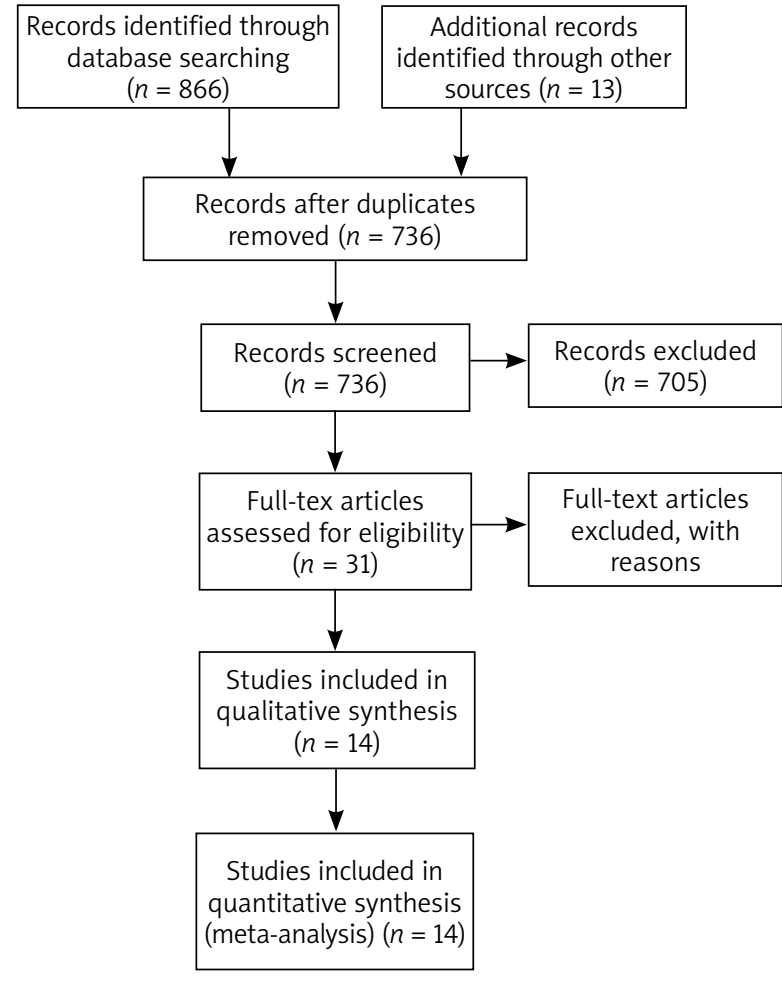

Figure 1. Study flow diagram illustrating details of search strategy and study selection processes

showed significant results ( $R R=1.03,95 \% \mathrm{Cl}$ : 0.95-1.12; $\mathrm{RR}=1.39,95 \% \mathrm{Cl}$ : 0.90-2.16). Otherwise, collective analysis of these two comparisons indicated that TCl therapy is slightly more effective than TCS one $(\mathrm{RR}=1.24,95 \% \mathrm{Cl}$ : 1.06-1.44). In order to support described results, quantitative analysis of secondary outcomes, EASI, mEASI and affected BSA, was planned. EASI is an instrument used to score the extent and severity of AD. Its compositions cover ratings of four signs: erythema, oedema/induration/papulation, excoriations, lichenification and affected BSA [28]. mEASI is a modification of EASI, which additionally includes assessment of itch [19, 22]. BSA simply describes the percentage of the area affected by AD. Unfortunately, data reported in included studies were incoherently presented or some of them lacked details such as standard deviations, standard errors, mean difference or confidence interval. Consequently, quantitative analysis was impossible to carry out. However, few trials reported significant differences between examined treatments. All these trials examined least potent to lower mid-strength corticosteroids. TCI treatment was reported to cause a greater improvement in terms of mEASI in two studies $[16,19](p<0.01)$, in terms of BSA in four studies $[15,18,19,21](p<0.05)$ and EASI in two studies [19, $22](p<0.05)$. Albeit, TCS treatment was shown to cause a better mEASI improvement in one study [21] ( $p=0.018)$,
BSA improvement in another study [20] ( $p \leq 0.006)$ and EASI improvement in also another one [23] ( $p \leq 0.006)$.

\section{Overall number of AEs}

The outcomes were addressed in all studies comparing mid-strength to potent TCS and four studies comparing least potent to lower mid-strength TCS. Any of these comparisons or pooled estimate of them did not produce significant results (Figure 3).

\section{Skin burning and pruritus events}

A number of studies [2, 15, 17, 19, 21, 24] indicated skin burning and pruritus as the most common AEs accompanied with AD treatment. TCI therapy in all computed comparisons (Figures 4 and 5) cause more skin burning or pruritus events ( $R R=3.32,95 \% \mathrm{Cl}$ : 2.90-3.80; $\mathrm{RR}=1.59,95 \% \mathrm{Cl}: 1.34-1.80$, respectively).

\section{Discussion}

Long-standing research of $A D$ reveals many novel options for its treatment with $\mathrm{TCl}$ as an example. The efficacy of TCl treatment is undisputed [4], albeit their safety were called into question in 2005, when the US FDA recommended a 'black box' warning, which represents serious or life-threating risks. The indication was improperly assigned because of the insufficient data concerning long-time safety and risk of cancer [29]. Currently, $\mathrm{TCl}$ are recommended as a second-line therapy [30], while they should be considered on an equal level as the alternative option for TCS. Consequently, studies examining $\mathrm{TCl}$ safety on a larger population of patients are expedient. This study aimed at efficacy and safety examination of $\mathrm{TCl}$ therapy in comparison with standard corticosteroids therapy. The review included only data comparing TCI with TCS, leaving behind similar comparisons for example of tacrolimus vs. a combination of TCS and tacrolimus [21]. The current review showed a slight dominance of TCl over TCS in terms of efficacy (Figure 2) when comparing $\mathrm{TCl}$ with both defined subgroups: least potent to lower mid-strength or mid-strength to potent TCS. Unfortunately, TCI failed to demonstrate greater safety, its treatment elicits a higher number of AEs (Figures 4 and 5). Additionally, primary outcomes were not supported by additional evidence (EASI, mEASI or affected BSA). Results presented in the current study are in accordance with the ones published earlier [4, 31-37]. The adjudication equivalence might have happened because the majority of included trials were common for all metaanalysis. Nevertheless, until now this study has included the largest number of children and adults raising the advantage over the former studies. Some of meta-analyses mentioned above focused only on paediatric patients [31, 34, 36], placed pimecrolimus as a control group [4, $31,34]$, lacked data concerning safety [32] or efficacy of 
Table 1. Characteristics of included trials

\begin{tabular}{|c|c|c|c|c|c|}
\hline Study & Therapy & $N$ & $\begin{array}{l}\text { Duration } \\
\text { [weeks] }\end{array}$ & Location & $\begin{array}{c}\text { Age of } \\
\text { participants }\end{array}$ \\
\hline \multirow{2}{*}{$\begin{array}{l}\text { Bieber } 2007 \\
\text { [26] }\end{array}$} & Tacrolimus $0.03 \%$ & 136 & \multirow[t]{2}{*}{3} & \multirow[t]{2}{*}{ Multi-centre } & \multirow[t]{2}{*}{ Children } \\
\hline & Methylprednisolone aceponate $0.1 \%$ & 129 & & & \\
\hline \multirow{2}{*}{$\begin{array}{l}\text { Doss } 2009 \\
\text { [2] }\end{array}$} & Tacrolimus $0.1 \%$ & 288 & \multirow[t]{2}{*}{3} & \multirow[t]{2}{*}{ Multi-centre } & \multirow[t]{2}{*}{ Adults } \\
\hline & Fluticasone $0.005 \%$ & 280 & & & \\
\hline \multirow{2}{*}{$\begin{array}{l}\text { Doss } 2010 \\
\text { [24] }\end{array}$} & Tacrolimus $0.03 \%$ & 240 & \multirow[t]{2}{*}{6} & \multirow[t]{2}{*}{ Multi-centre } & \multirow[t]{2}{*}{ Children } \\
\hline & Fluticasone $0.005 \%$ & 239 & & & \\
\hline \multirow{2}{*}{$\begin{array}{l}\text { Hofman } 2006 \\
\text { [18] }\end{array}$} & Tacrolimus $0.03 \%$ & 121 & \multirow[t]{2}{*}{28} & \multirow[t]{2}{*}{ Multi-centre } & \multirow[t]{2}{*}{ Children } \\
\hline & Hydrocortisone acetate $0.1 \%$ and hydrocortisone butyrate $1 \%$ & 111 & & & \\
\hline \multirow{2}{*}{$\begin{array}{l}\text { Luger } 2001 \\
\text { [25] }\end{array}$} & Pimecrolimus 1\% & 45 & \multirow[t]{2}{*}{3} & \multirow[t]{2}{*}{ Multi-centre } & \multirow[t]{2}{*}{ Adults } \\
\hline & Betamethasone valerate $0.1 \%$ & 42 & & & \\
\hline \multirow{2}{*}{$\begin{array}{l}\text { Luger } 2004 \\
\text { [23] }\end{array}$} & Pimecrolimus 1\% & 328 & \multirow[t]{2}{*}{52} & \multirow[t]{2}{*}{ Multi-centre } & \multirow[t]{2}{*}{ Adults } \\
\hline & Triamcinolone acetonide $0.1 \%$ and hydrocortisone acetate $1 \%$ & 330 & & & \\
\hline \multirow{2}{*}{$\begin{array}{l}\text { Mandelin } \\
2010[22]\end{array}$} & Tacrolimus $0.1 \%$ & 40 & \multirow[t]{2}{*}{52} & \multirow[t]{2}{*}{ Single-centre } & \multirow[t]{2}{*}{ Adults } \\
\hline & Hydrocortisone butyrate $0.1 \%$ and hydrocortisone acetate $1 \%$ & 40 & & & \\
\hline \multirow{2}{*}{$\begin{array}{l}\text { Neumann } \\
2008 \text { [27] }\end{array}$} & Tacrolimus $0.1 \%$ & 20 & \multirow[t]{2}{*}{87} & \multirow[t]{2}{*}{ Single-centre } & \multirow[t]{2}{*}{ Adults } \\
\hline & corticosteroids regimen & 20 & & & \\
\hline Reitamo & Tacrolimus $0.03 \%$ or Tacrolimus $0.1 \%$ & 189/186 & 3 & Multi-centre & Adults \\
\hline $200<a[26]$ & Hydrocortisone acetate $1 \%$ & 185 & & & \\
\hline Reitamo & Tacrolimus $0.03 \%$ or Tacrolimus $0.1 \%$ & 193/191 & 3 & Multi-centre & Children \\
\hline 2002b [15] & Hydrocortisone butyrate $0.1 \%$ & 186 & & & \\
\hline Reitamo 2004 & Tacrolimus $0.03 \%$ & 210 & 3 & Multi-centre & Children \\
\hline & Hydrocortisone acetate $1 \%$ & 207 & & & \\
\hline Reitamo 2005 & Tacrolimus $0.1 \%$ & 487 & 26 & Multi-centre & Adults \\
\hline & Hydrocortisone butyrate $0.1 \%$ and hydrocortisone acetate $1 \%$ & 485 & & & \\
\hline Sigurgeirsson & Pimecrolimus 1\% & 1205 & 260 & Multi-centre & Children \\
\hline 2015 [20] & Hydrocortisone acetate $1 \%$ and hydrocortisone butyrate $0.1 \%$ & 1213 & & & \\
\hline Sikder 2005 & Tacrolimus $0.03 \%$ & 15 & 4 & Multi-centre & Children \\
\hline & Clobetasone butyrate $0.05 \%$ & 15 & & & \\
\hline
\end{tabular}

treatment [36]. One review [35] focused on pro-reactive treatment despite the reactive one. Many of them included the vehicle into comparison [31-33], while that evaluation does not express the decision making process between choosing TCl or TCS.

The current review examined 7376 patients with moderate or severe AD, all participants applied topical ointments twice daily. Group sizes were various and ranged from 15 to 1213 participants, although sizes of pooled populations were close (3894 patients applying $\mathrm{TCl}, 3482$ corticosteroids). The methodological quality of 14 trials, based on risk of bias assessment, was good. All studies were free of other sources of bias and did not report their outcomes selectively. Eleven out of 14 trials were investigator-blinded ones, in 12 blinding of participants or personnel were described. Only two studies did not mention any operation to deal with incomplete outcome data. Random sequence generation was not described in one trial. Allocation concealment was not reported in majority of trials. Quality of evidence questions the results of current review. Main outcomes evaluating the efficacy were assessed to provide very low quality of evidence assessed using GRADE score. Adverse events (skin burning or pruritus) outcomes were estimated to have moderate quality. These results were probably induced by different characteristics of trials with an example of diversified age among participants in examined studies. Both adults (at least 16 years old) [2, 16, 19, 22, $23,25,27]$ and children (2-15 years) [15, 17, 18, 20, 21, 24, 26] were incorporated. Surprisingly, despite age-dependent treatment recommendations, no substantial differences between children and adults were observed in this 


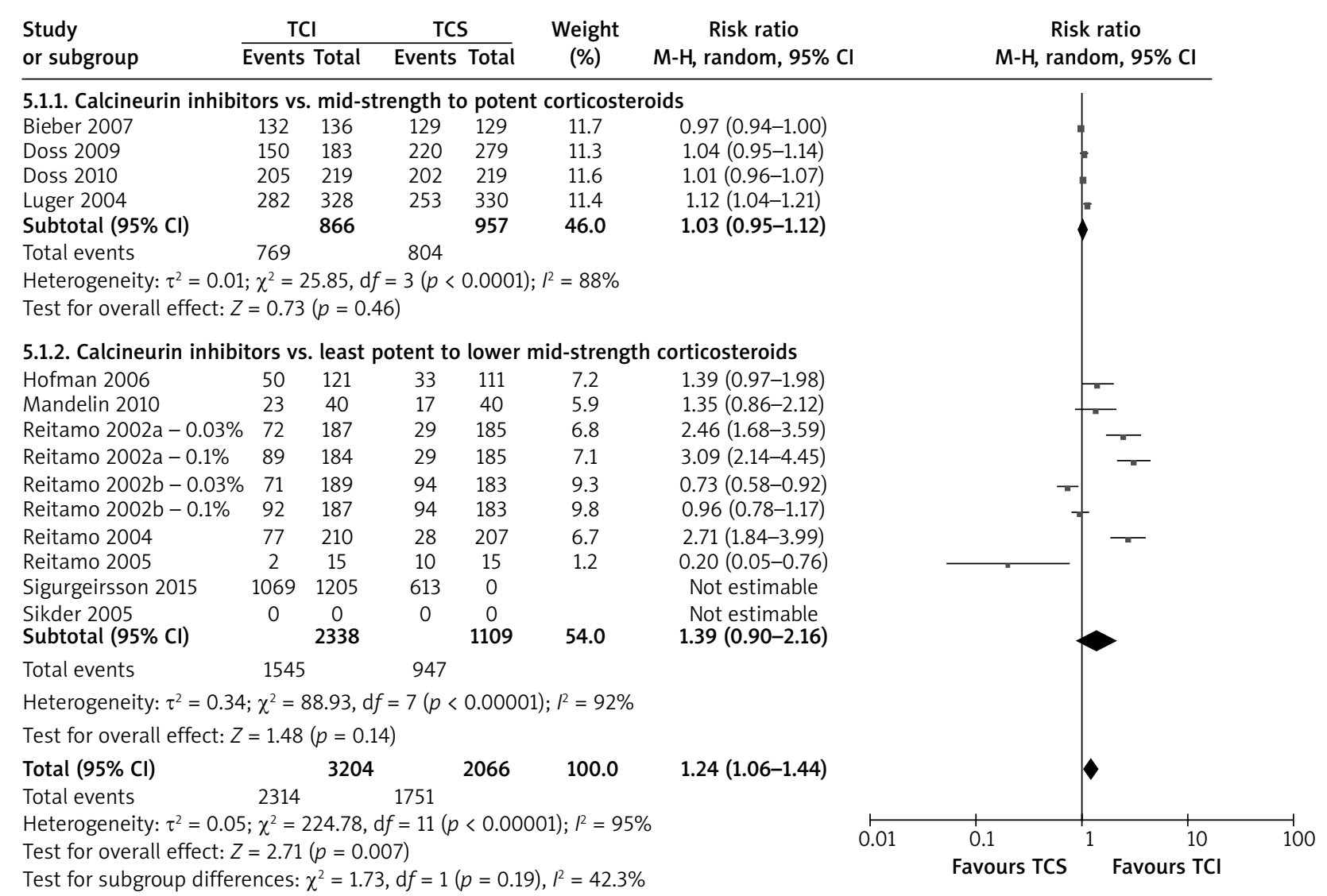

$\mathrm{Cl}$ - confidence interval, $\mathrm{M}-\mathrm{H}$-Mantel-Haenszel.

Figure 2. Physician's assessment of global response of improvement: clear or excellent. For citation references, see Table 1

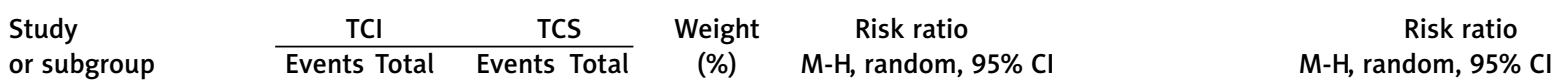

\begin{tabular}{lcccccc}
\hline 5.2.1. Calcineurin inhibitors vs. mid-strength & to potent & corticosteroids \\
Bieber 2007 & 6 & 136 & 0 & 129 & 0.5 & $12.34(0.70-216.79)$ \\
Doss 2009 & 75 & 287 & 42 & 179 & 11.5 & $1.11(0.80-1.55)$ \\
Doss 2010 & 29 & 219 & 30 & 219 & 8.7 & $0.97(0.60-1.55)$ \\
Luger 2001 & 32 & 45 & 19 & 42 & 10.4 & $1.57(1.07-2.30)$ \\
Luger 2004 & 256 & 328 & 240 & 330 & 15.7 & $1.07(0.98-1.17)$ \\
Subtotal (95\% Cl) & & 1015 & & $\mathbf{8 9 9}$ & $\mathbf{4 6 . 9}$ & $1.16(0.95-1.41)$ \\
Total events & 398 & & 331 & & &
\end{tabular}

Heterogeneity: $\tau^{2}=0.02 ; \chi^{2}=6.91, \mathrm{~d} f=4(p=0.14) ; P^{2}=42 \%$

Test for overall effect: $Z=1.42(p=0.16)$

5.2.2. Calcineurin inhibitors vs. least potent to lower mid-strength corticosteroids

\begin{tabular}{lllllll} 
Hofman 2006 & 10 & 133 & 97 & 124 & 6.8 & 0.10 \\
\hline & $0.05-0.18)$
\end{tabular}

$\begin{array}{lllllll}\text { Mandelin } 2010 & 40 & 40 & 32 & 40 & 14.8 & 1.25(1.06-1.46)\end{array}$

$\begin{array}{lllllll}\text { Reitamo } 2005 & 329 & 487 & 206 & 485 & 15.3 & 1.59(1.41-1.79)\end{array}$

$\begin{array}{lllllll}\text { Sigurgeirsson } 2015 & 1162 & 1205 & 1160 & 1213 & 16.2 & 1.01(0.99-1.02)\end{array}$

$\begin{array}{lllll}\text { Subtotal }(95 \% \mathrm{Cl}) & 1865 & 1862 & 53.1 & 0.81(0.55-1.20)\end{array}$

Total events $1541 \quad 1495$

Heterogeneity: $\tau^{2}=0.14 ; \chi^{2}=122.45, \mathrm{~d} f=3(p<0.00001) ; P^{2}=98 \%$

Test for overall effect: $Z=1.04(p=0.30)$

\begin{tabular}{|c|}
\hline otal $(95 \% \mathrm{Cl})$ \\
\hline Total events \\
\hline
\end{tabular}

Heterogeneity: $\tau^{2}=0.07 ; \chi^{2}=140.30, \mathrm{~d} f=8(p<0.00001) ; l^{2}=94 \%$

Test for overall effect: $Z=0.25(p=0.81)$

Test for subgroup differences: $\chi^{2}=2.46, \mathrm{~d} f=1(p=0.12), p^{2}=59.4 \%$

$\mathrm{Cl}$ - confidence interval, $\mathrm{M}-\mathrm{H}$-Mantel-Haenszel.

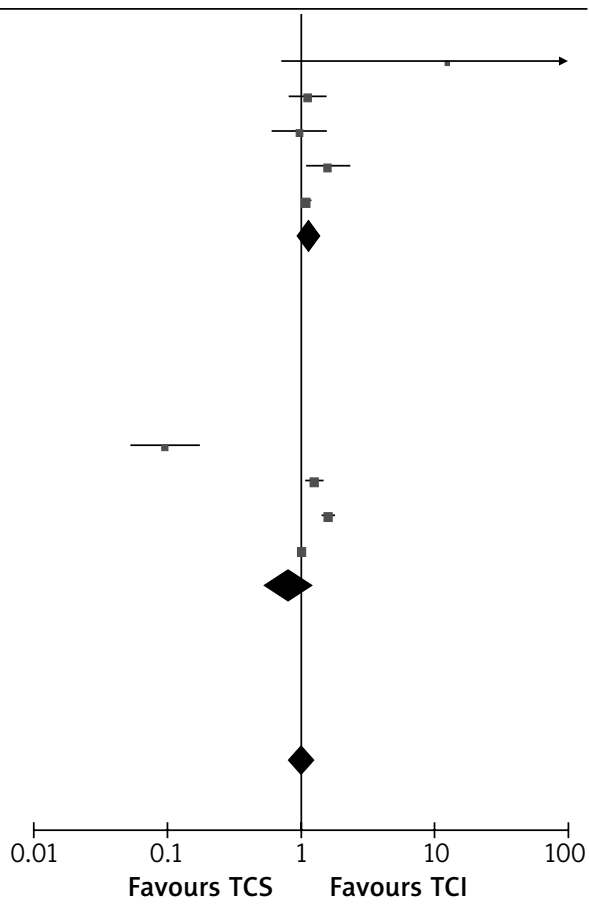

Figure 3. Any adverse events. For citation references, see Table 1 


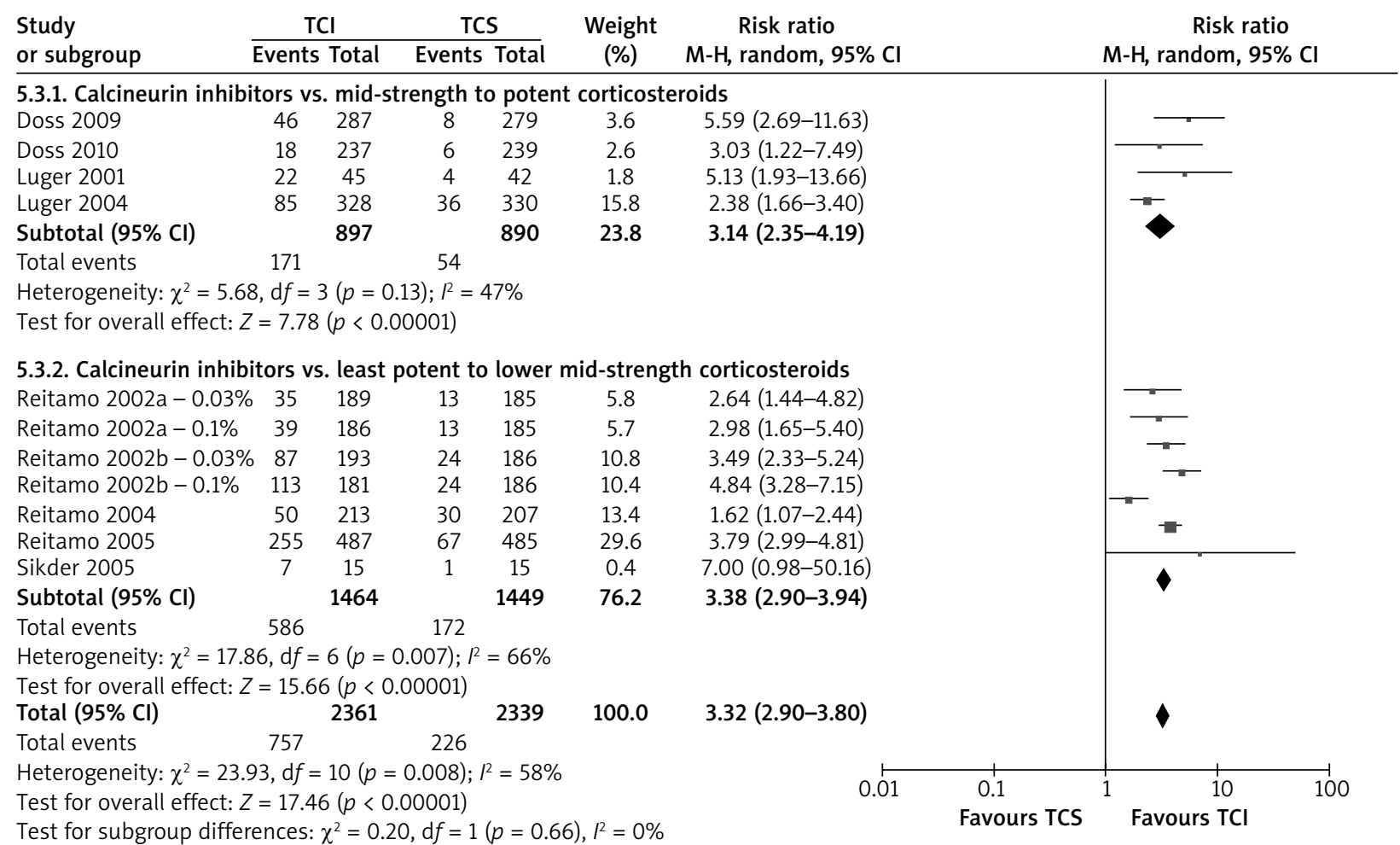

$\mathrm{Cl}$ - confidence interval, $\mathrm{M}-\mathrm{H}-$ Mantel-Haenszel.

Figure 4. Skin burning. For citation references, see Table 1

\begin{tabular}{llll}
$\mathrm{TCl}$ & $\mathrm{TCS}$ & Weight & Risk ratio \\
\cline { 2 - 4 } & Study ratio
\end{tabular}

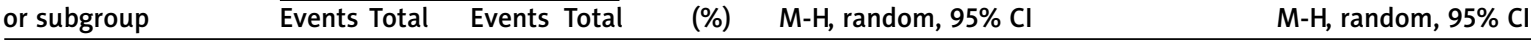
5.4.1. Calcineurin inhibitors vs. mid-strength to potent corticosteroids

$\begin{array}{lllllll}\text { Doss } 2009 & 18 & 328 & 6 & 330 & 3.2 & 3.02(1.21-7.51)\end{array}$

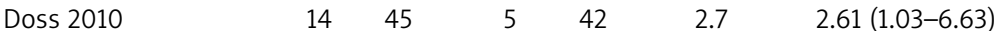

$\begin{array}{lllllll}\text { Luger } 2001 & 13 & 237 & 8 & 239 & 4.2 & 1.64(0.69-3.88)\end{array}$

$\begin{array}{lllllll}\text { Luger } 2004 & 9 & 287 & 6 & 279 & 3.2 & 1.46(0.53-4.04)\end{array}$

$\begin{array}{lllll}\text { Subtotal }(95 \% \mathrm{Cl}) & 897 & 890 & 13.4 & 2.12(1.34-3.36)\end{array}$

Total events $\quad 54 \quad 25$

Heterogeneity: $\chi^{2}=1.63, \mathrm{~d} f=3(p=0.65) ; l^{2}=0 \%$

Test for overall effect: $Z=3.22(p=0.001)$

5.4.2. Calcineurin inhibitors vs. least potent to lower mid-strength corticosteroids

$\begin{array}{lllllll}\text { Reitamo } 2002 a-0.03 \% & 25 & 189 & 14 & 185 & 7.5 & 1.75(0.94-3.26)\end{array}$

$\begin{array}{lllllll}\text { Reitamo } 2002 \mathrm{a}-0.1 \% & 21 & 186 & 14 & 185 & 7.5 & 1.49(0.78-2.84)\end{array}$

$\begin{array}{lllllll}\text { Reitamo } 2002 \mathrm{~b}-0.03 \% & 39 & 193 & 18 & 186 & 9.7 & 2.09(1.24-3.52)\end{array}$

$\begin{array}{lllllll}\text { Reitamo } 2002 b-0.1 \% & 29 & 191 & 18 & 186 & 9.7 & 1.57(0.90-2.73)\end{array}$

$\begin{array}{lllllll}\text { Reitamo 2004 } & 45 & 210 & 33 & 207 & 17.6 & 1.34(0.90-2.02)\end{array}$

$\begin{array}{lllllll}\text { Reitamo } 2005 & 88 & 487 & 65 & 485 & 34.6 & 1.35(1.00-1.81)\end{array}$

$\begin{array}{lllll}\text { Subtotal }(95 \% \mathrm{Cl}) & 1456 & 1434 & 86.6 & 1.50(1.25-1.81)\end{array}$

Total events $\quad 247 \quad 162$

Heterogeneity: $\chi^{2}=2.59, \mathrm{~d} f=5(p=0.76) ; P^{2}=0 \%$

Test for overall effect: $Z=4.34(p<0.0001)$

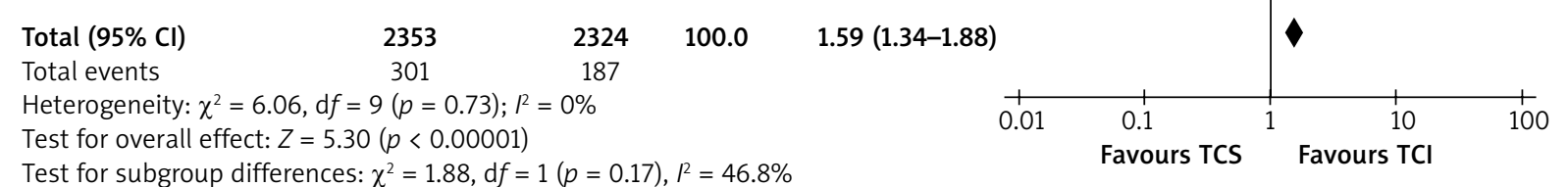

$\mathrm{Cl}$ - confidence interval, $\mathrm{M}-\mathrm{H}$-Mantel-Haenszel.

Figure 5. Pruritus. For citation references, see Table 1 
review. Only one study [17] incorporating children and two incorporating adults $[16,23]$ revealed TCI treatment to be significantly more effective than TCS only. Safety analysis, presented in Figures 3-5, demonstrated more consistent results. Another limitation of this analysis, which might induce the quality of results, were different follow-up times applied in included studies: short-term (a few weeks) [2, 15-17, 21, 24-26] and long-term [18-20, 22, 23, 27] observations were assessed together. More serious AEs, with skin atrophy as a convenient example [30], appears after chronic use, what cannot be assessed in short-term observations. Skin atrophy is a result of steroid-dependent suppression of collagen synthesis in connective tissue. Calcineurin inhibitors are shown to have greater specificity and no impact on connective tissue [38]. Despite weaknesses presented above, the power of the current review might be considered substantial. Reviews were carried out on a population of 7376 and revealed statistically significant differences in treatment efficacy in favour of TCl and in treatment safety in favour of TCS.

\section{Conclusions}

$\mathrm{TCl}$ treatment might be slightly more efficient than $A D$ treatment. Contrarily they are associated with more incidences of AEs, such as skin burning or pruritus. Albeit, standardized recommendations for reporting outcomes and interventions should be developed to ease the analysis of a subject in question. Another issue, which impedes the analysis, is still too small number of long-term trials. Along with a greater number of existing trials, more variables, like age of participants, followup time or drug potency, could be accommodated into meta-analysis. Complex analysis, incorporating these variables simultaneously, would provide credible safety and efficacy data, and consequently novel guidance for AD therapy.

\section{Conflict of interest}

The authors declare no conflict of interest.

\section{References}

1. Hanifin J, Rajka G. Diagnostic features of atopic dermatitis. Acta Derm Venereol Suppl Stockh 1980; 92 (Suppl): 44-7.

2. Doss N, Reitamo S, Dubertret L, et al. Superiority of tacrolimus $0.1 \%$ ointment compared with fluticasone $0.005 \%$ in adults with moderate to severe atopic dermatitis of the face: results from a randomized, double-blind trial. Br J Dermatol 2009; 161: 427-34.

3. Eichenfield LF, Tom WL, Chamlin SL, et al. Guidelines of care for the management of atopic dermatitis: section 1. Diagnosis and assessment of atopic dermatitis. J Am Acad Dermatol 2014; 70: 338-51.
4. Cury Martins J, Martins C, Aoki V, et al. Topical tacrolimus for atopic dermatitis. Cochrane Database Syst Rev 2015; 7: CD009864.

5. Addor FAS, Aoki V. Skin barrier in atopic dermatitis. An Bras Dermatol 2010; 85: 184-94.

6. Kim BE, Leung DYM. Significance of skin barrier dysfunction in atopic dermatitis. Allergy Asthma Immunol Res 2018; 10: 207-15.

7. Lewis-Jones MS, Finlay AY, Dykes PJ. The Infants' Dermatitis Quality of Life Index. Br J Dermatol 2001; 144: 104-10.

8. Misery L, Finlay AY, Martin N, et al. Atopic dermatitis: impact on the quality of life of patients and their partners. Dermatol Basel Switz 2007; 215: 123-9.

9. Darsow U, Wollenberg A, Simon, D, et al. ETFAD/EADV eczema task force 2009 position paper on diagnosis and treatment of atopic dermatitis. J Eur Acad Dermatol Venereol 2010; 24: 317-28.

10. Czarnecka-Operacz M. New treatment algorithm of mild-tomoderate atopic dermatitis: recommendations for pimecrolimus 1\% cream in the topical approach. Alergoprofil 2014; 4: 4.

11. Thaçi D, Salgo R. The topical calcineurin inhibitor pimecrolimus in atopic dermatitis: a safety update. Acta Dermatovenerol Alp Pannonica Adriat 2007; 16: 58, 60-2.

12. Moher D, Liberati A, Tetzlaff J, Altman DG; PRISMA Group. Preferred reporting items for systematic reviews and meta-analyses: the PRISMA statement. PLoS Med 2009; 6: e1000097.

13. Ryan R, Hill S. How to GRADE the quality of the evidence. Cochrane Consumers and Communication Group. Available at http://cccrg.cochrane.org/author-resources. Version 3.0; December 2016.

14. Higgins J, Green S. Cochrane Handbook for Systematic Reviews of Interventions. Wiley Online Books. Available at https://onlinelibrary.wiley.com/doi/book/10.1002/9780470712184. Accessed January 23, 2019.

15. Reitamo S, Rustin M, Ruzicka T, et al. Efficacy and safety of tacrolimus ointment compared with that of hydrocortisone butyrate ointment in adult patients with atopic dermatitis. J Allergy Clin Immunol 2002; 109: 547-55.

16. Reitamo S, Van Leent EJM, Ho V, et al. Efficacy and safety of tacrolimus ointment compared with that of hydrocortisone acetate ointment in children with atopic dermatitis. J Allergy Clin Immunol 2002; 109: 539-46.

17. Reitamo S, Harper J, Bos JD, et al. $0.03 \%$ Tacrolimus ointment applied once or twice daily is more efficacious than $1 \%$ hydrocortisone acetate in children with moderate to severe atopic dermatitis: results of a randomized double-blind controlled trial. Br J Dermatol 2004; 150: 554-62.

18. Hofman T, Cranswick N, Kuna P, et al. Tacrolimus ointment does not affect the immediate response to vaccination, the generation of immune memory, or humoral and cell-mediated immunity in children. Arch Dis Child 2006; 91: 905-10.

19. Reitamo S, Ortonne JP, Sand C, et al. A multicentre, randomized, double-blind, controlled study of long-term treatment with $0 \cdot 1 \%$ tacrolimus ointment in adults with moderate to severe atopic dermatitis. Br J Dermatol 2005; 152: 1282-9.

20. Sigurgeirsson B, Boznanski A, Todd G, et al. Safety and efficacy of pimecrolimus in atopic dermatitis: a 5-year randomized trial. Pediatrics 2015; 135: 597-606.

21. Sikder MAU, Mamun SA, Khan RM, et al. Topical $0.03 \%$ tacrolimus ointment, $0.05 \%$ clobetasone butyrate cream alone and their combination in older children with atopic derma- 
titis - an open randomized comparative study. J Pak Assoc Dermatol 2016; 15: 304-12.

22. Mandelin J, Remitz A, Virtanen H, Reitamo S. One-year treatment with $0.1 \%$ tacrolimus ointment versus a corticosteroid regimen in adults with moderate to severe atopic dermatitis: a randomized, double-blind, comparative trial. Acta Derm Venereol 2010; 90: 170-4.

23. Luger TA, Lahfa M, Fölster-Holst R, et al. Long-term safety and tolerability of pimecrolimus cream $1 \%$ and topical corticosteroids in adults with moderate to severe atopic dermatitis. J Dermatol Treat 2004; 15: 169-78.

24. Doss N, Kamoun MR, Dubertret L, et al. Efficacy of tacrolimus $0.03 \%$ ointment as second-line treatment for children with moderate-to-severe atopic dermatitis: evidence from a randomized, double-blind non-inferiority trial vs. fluticasone 0.005\% ointment. Pediatr Allergy Immunol 2010; 21: 321-9.

25. Luger T, Leent EJMV, Graeber M, et al. SDZ ASM 981: an emerging safe and effective treatment for atopic dermatitis. Br J Dermatol 2001; 144: 788-94.

26. Bieber T, Vick K, Fölster-Holst R, et al. Efficacy and safety of methylprednisolone aceponate ointment $0.1 \%$ compared to tacrolimus $0.03 \%$ in children and adolescents with an acute flare of severe atopic dermatitis. Allergy 2007; 62: 184-9.

27. Neumann E, Amtage D, Bruckner-Tuderman L, Mockenhaupt M. A single-center open-label long-term comparison of tacrolimus ointment and topical corticosteroids for treatment of atopic dermatitis. J Dtsch Dermatol Ges 2008; 6: 548-53.

28. Leshem YA, Hajar T, Hanifin JM, Simpson EL. What the Eczema Area and Severity Index score tells us about the severity of atopic dermatitis: an interpretability study. Br I Dermatol 2015; 172: 1353-7.

29. Ring J, Möhrenschlager M, Henkel V. The US FDA 'Black Box' warning for topical calcineurin inhibitors. Drug Saf 2008; 31: 185-98.

30. Wollenberg A, Barbarot S, Bieber T, et al. Consensus-based European guidelines for treatment of atopic eczema (atopic dermatitis) in adults and children: part I. J Eur Acad Dermatol Venereol 2018; 32: 657-82.

31. Yan J, Chen SL, Wang XL, et al. Meta-analysis of tacrolimus ointment for atopic dermatitis in pediatric patients. Pediatr Dermatol 2008; 25: 117-20.

32. El-Batawy MMY, Bosseila MAW, Mashaly HM, Hafez VSGA. Topical calcineurin inhibitors in atopic dermatitis: a systematic review and meta-analysis. J Dermatol Sci 2009; 54: 76-87.

33. Ashcroft DM, Dimmock P, Garside R, et al. Efficacy and tolerability of topical pimecrolimus and tacrolimus in the treatment of atopic dermatitis: meta-analysis of randomised controlled trials. BMJ 2005; 330: 516.

34. Chen SL, Yan J, Wang FS. Two topical calcineurin inhibitors for the treatment of atopic dermatitis in pediatric patients: a meta-analysis of randomized clinical trials. J Dermatol Treat 2010; 21: 144-56.

35. Schmitt J, von Kobyletzki L, Svensson A, Apfelbacher C. Efficacy and tolerability of proactive treatment with topical corticosteroids and calcineurin inhibitors for atopic eczema: systematic review and meta-analysis of randomized controlled trials. Br J Dermatol 2011; 164: 415-28.

36. Siegfried EC, Jaworski JC, Kaiser JD, Hebert AA. Systematic review of published trials: long-term safety of topical corticosteroids and topical calcineurin inhibitors in pediatric patients with atopic dermatitis. BMC Pediatr 2016; 16: 75.

37. Broeders JA, Ahmed Ali U, Fischer G. Systematic review and meta-analysis of randomized clinical trials (RCTs) comparing topical calcineurin inhibitors with topical corticosteroids for atopic dermatitis: a 15-year experience. J Am Acad Dermatol 2016; 75: 410-9.e3.

38. Reitamo S, Rissanen J, Remitz A, et al. Tacrolimus ointment does not affect collagen synthesis: results of a single-center randomized trial. J Investig Dermatol 1998; 111: 396-8. 